water Fig. 3 is produced, but more delicate and more regular than that obtained with litmus.

Azure Blue.-The aqueous and alcoholic solutions of azure-blue or pearl form figures similar to those already described. In acidulated water we obtain a very regular spheroidal nucleus of a very dark blue, surrounded by a spheroidal layer with an inferior stem (No. 6).

Cochineal.- The aqueous solution forms in acidulated water the figure No. 3, regular, like that of litmus and of lake. In salt water, cochineal, not being soluble, is precipitated and the phenomenon is not produced.

Iodine.-The alcoholic tincture of iodine forms, in sugared, salt, or acidulated water, beautiful figures almost identical with those of the colours of the aniline solution.

Bichromate of Potash.-To make the experiments with bichromate of potash succeed I changed the arrangement of the experiment on account of the very great density of the solution in comparison with the density of water. I fill the vessel in the usual manner, then I place above the vessel a small funnel, fitted with a capillary tube which partly enters the liquid. The aqueous solution of bichromate of potash being poured into the small funnel, flows out, forming a small descending spiral, which usually is arrested in the division between the more and less dense parts of the liquid. In acidulated or salt water two very beautiful figures are formed resembling those of Nos. 2 and 5 , but reversed.

The various experiments described above have been repeated several times for each colour, and I have always obtained the same results. This persistence of form shows that the phenomenon is regulated by a law which I shall seek to discover. I believe I may conclude from these first attempts that the form of the figure depends on the liquid in which the colour is dissolved, more than on the colour itself. By employing other acids and other salts, not such, however, as precipitate the colour, it is probable that other figures would be obtained.

\section{TRACES OF EARLY MAN IN YAPAN}

$\mathrm{SO}$ much interest is felt in the origin of the Japanese, $D$ that any information regarding earlier races in Japan will interest the readers of NATURE.

The discovery and examination of a genuine kjockkenmoedding, or shell heap, enables me to give positive evidences regarding a prehistoric race who occupied this island. Whether autocthonous or not it would of course be impossible to say. On my first ride to Tokio, in June of this year, I observed, from the car window, near a station called Omori, a fine section of a shell heap, which was recognised as such at once, from its resemblance to those I had often studied along the coast of New England. On September 16, accompanied by Messrs. Matsumura, Matsura, and Sasaki, three intelligent Japanese students, I made an examination of it, and a few days afterwards, in company with Dr. David Murray, Superintendent of Public Instruction, and Mr. Vukuyo, with two coolies to do the heavy digging; made an exhaustive exploration of it.

The deposit is composed of shells of various genera, such as Vusus, Eburna, Turbo, Pyrula, Arca, Pecten, Cardium, two strongly marked species of Ostrea, and curiously enough, Mya arenaria, not to be distinguished from the New England form, as well as other genera. These shells, so far as I know, still live in the Bay of Yedo. The heap is about 200 feet wide, and varies from a foot to five or six feet in thickness, with a deposit of earth above, at least three feet in thickness. It is now nearly half a mile from the shore of the Bay, though in accordance with the usual position of these heaps in other parts of the world, it must have been formed near the shore, and this fact indicates a considerable elevation of the land since the deposits were made. I may add that other evidences of a geological nature indicate a wide-spread upheaval in past times.

The peculiarities of the typical shell-heap, such as fragments of bones, rough implements worked out of horn, and pieces of pottery, are all here. The heap, however, is marked by certain features which render it peculiar.

First, the immense quantity of pottery and its diversity of ornamentation, some of it extremely ornate, but very rude.

Second, the absence of bone-implements, the few found-eight or ten in number-being of horn, with the exception of an arrow-head of diminutive proportions, made of the tusk of a wild boar. All the implements are very simple ; two of them are like blunt bone awls, with the end very obtuse, and a constriction worked around the end. Another one is made from the natural termination of a deer's antler. A few fragments of horn were found which had been cut off at the ends.

Third, the entire absence of flint flakes, or stone implements of any kind, if we except a small stone adze found near the top of the heap, and made out of a soft sandstone. The frequent occurrence of isolated tusks of the wild boar would seem to indicate that these teeth were used for implements, and one piece of antler, having a hole in the end, is worked in the form of a rude handle. By far the most common bones found were those of the deer and wild boar, and curiously enough Steenstrup shows the same proportion in the Danish shell heaps. No human bones have yet been found.

An analysis of the red pigment found on some of the pottery shows it to be cinnabar. With its removal from the shore, its elevation above the level of the sea, the absence of stone implements, and the great thickness of the earth deposits above, we have reasons for believing that the deposit is of high antiquity.

Through the intelligent interest manifested by $\mathrm{Mr}$. Kato and Mr. Hamao, Director and Vice-Director of the Imperial University of Tokio, every facility for a thorough investigation of these deposits will be given me.

Tokio, Japan, September 2 I EDWARD S. Morse

\section{NOTES}

IT is proposed to hold the next annual meeting of the Asso. ciation for the Improvement of Geometrical Teaching (under the presidency of Dr. Hirst) at University College, Gower Street, on January II, I878, at 10.30 A.M. Four resolutions are to be submitted to the Association:-1. That in the opinion of this Association it is both reasonable and expedient that candidates at all examinations in elementary geometry should be required to give evidence of such ability as is necessary for the solving of easy geometrical exercises; and that the secretaries of the Association be instructed to send a copy of this resolution to the leading examining bodies of the country. The other resolutions relate to the proposed formation of sub-committees for drawing up a syllabus of (I) Solid Geometry, (2) Higher Plane Geometry (Transversals, Projection, \&c.), (3) Geometrical Conics. It may be in the recollection of our readers that the report of the British Association Committee (in 1876 , published at the time in NATURE), was highly favourable to the work of this Association.

THE dissection of the Berlin gorilla was performed last week by Prof. Virchow and Prof. Hartmann in the presence of several prominent Berlin physicians, and it was ascertained that the sudden death of the animal was caused by acute inflammation of the bowels, the same disease which carries off young children so rapidly. The dissection explains the cause of his previous illnesses and supplies valuable information with regard to the treatment of anthropoidal apes. The button of a glove, iron wire, and pins were found in Pongo's stomach. 